\title{
Type 2 diabetes impairs pulmonary function in morbidly obese women: a case-control study
}

\author{
A. Lecube • G. Sampol • X. Muñoz • C. Hernández • \\ J. Mesa $\cdot$ R. Simó
}

Received: 11 September 2009 / Accepted: 27 January 2010/Published online: 9 March 2010

(C) Springer-Verlag 2010

\begin{abstract}
Aims/hypothesis To determine whether the presence of type 2 diabetes and the degree of metabolic control are related to reduced pulmonary function in obese individuals.

Methods Seventy-five morbidly obese women (25 with type 2 diabetes [cases] — and 50 without diabetes [controls]) with a history of non-smoking and without prior cardiovascular or respiratory disease were prospective recruited for a casecontrol study in the outpatient obesity unit of a referral centre. Both groups were closely matched by age, BMI and waist circumference. Pulmonary function test included forced spirometry and static pulmonary volume measurements.

Results Type 2 diabetic patients showed lower forced expiratory volume at $1 \mathrm{~s}\left(\mathrm{FEV}_{1}\right)$ (mean difference $-11.6 \%$ of predicted [ $95 \% \mathrm{CI}-20.4$ to -2.8$] ; p=0.011)$, and $\mathrm{FEV}_{1} /$ forced vital capacity $\left(\mathrm{FEV}_{1} / \mathrm{FVC}\right)$ ratio (mean difference $-4.4 \%$ [95\% CI -8.1 to -0.7$] ; p=0.049$ ), but a greater residual volume (RV) (mean difference $19.5 \%$ of predicted [95\% CI 10.8-28.3]; $p<0.001$ ). In addition, an obstructive ventilatory pattern was more frequent in diabetic patients.
\end{abstract}

Electronic supplementary material The online version of this article (doi:10.1007/s00125-010-1700-5) contains supplementary material, which is available to authorised users.

A. Lecube $(\bowtie) \cdot$ C. Hernández $\cdot J$. Mesa $\cdot$ R. Simó

CIBER de Diabetes y Enfermedades Metabólicas Asociadas

(CIBERDEM), Instituto de Salud Carlos III (ISCIII), Diabetes and

Metabolism Research Unit, Institut de Recerca Hospital

Universitari Vall d'Hebron,

Passeig Vall d'Hebron, 119-129,

08035 Barcelona, Spain

e-mail: alecube@vhebron.net

G. Sampol $\cdot$ X. Muñoz

CIBER Enfermedades Respiratorias (CIBERES), Instituto de

Salud Carlos III (ISCIII), Sleep Unit, Pneumology Service,

Institut de Recerca Hospital Universitari Vall d'Hebron,

Barcelona, Spain
Significant negative correlations between $\mathrm{FEV}_{1}$ and fasting glucose, $\mathrm{HbA}_{1 \mathrm{c}}$ and HOMA insulin resistance (HOMA-IR) were detected. By contrast, RV was positively correlated with fasting glucose, $\mathrm{HbA}_{1 \mathrm{c}}$ and $\mathrm{HOMA}-\mathrm{IR}$. Multiple linear regression analyses showed that fasting glucose and $\mathrm{HbA}_{1 \mathrm{c}}$ independently predicted $\mathrm{FEV}_{1}$ and RV.

Conclusions/interpretation The presence of diabetes and the degree of glycaemic control are related to respiratory function impairment in morbidly obese women. Therefore, the impact of type 2 diabetes on pulmonary function should be taken into consideration by those providing care for obese people.

Keywords Obesity Pulmonary function · Type 2 diabetes

$\begin{array}{ll}\text { Abbreviations } \\ \mathrm{FEF}_{25-75} & \text { Maximum mid-expiratory flow } \\ \mathrm{FEV}_{1} & \text { Forced expiratory volume in } 1 \mathrm{~s} \\ \mathrm{FVC} & \text { Forced vital capacity } \\ \text { GOLD } & \begin{array}{l}\text { Global Initiative for Chronic Obstructive } \\ \text { Lung Disease }\end{array} \\ \text { HOMA-IR } & \text { Insulin resistance measured by HOMA } \\ \text { RV } & \text { Residual volume }\end{array}$

\section{Introduction}

The rapid increase of obesity prevalence during the last two decades has become one of the main threats to public health in the Western world. WHO predicts that by 2015 at least $10 \%$ of the projected global population will be obese [1]. This will constitute a significant health and economic burden, with associated increases in cardiovascular and metabolic disturbances, musculoskeletal disease and malignancy [2]. In addition, although there has been little focus on the impact of 
obesity on respiratory disease, there are clear effects on pulmonary function [3, 4]. Cross-sectional studies have demonstrated an inverse relationship between forced expiratory volume in $1 \mathrm{~s}\left(\mathrm{FEV}_{1}\right)$ and both BMI and waist circumference $[5,6]$. This is of particular importance because $\mathrm{FEV}_{1}$ is an independent predictor of all-cause mortality and a strong risk factor for cardiovascular disease, stroke and lung cancer [7]. The mechanical effects of truncal obesity and the metabolic effects of adipose tissue partly explain the impairment of pulmonary function in obese individuals [3].

Type 2 diabetes is another epidemic disease strongly associated with obesity. The relationship between both disorders is of such interdependence that the term 'diabesity' has been coined. Although the lung is not considered a target organ in type 2 diabetes, increasing evidence through crosssectional studies has appeared showing the opposite [8, 9]. In fact, diabetes is frequently co-morbid with chronic obstructive pulmonary disease [10], and data from the Atherosclerosis Risk in Communities Study showed a faster pulmonary function decline in type 2 diabetic patients than in other participants [11]. This is undeniably significant, because airflow limitation is an independent predictor of death in type 2 diabetes [12]. The available data suggest that the appearance of structural changes in respiratory muscle associated with insulin resistance $[13,14]$, non-enzymatic glycosylation of the connective tissue $[15,16]$, defects in the stimulation of pulmonary surfactant production [17] and the presence of a low-grade chronic inflammation state [18] should be considered among the possible mechanisms involved in this relationship. In support of these findings, thickening of the alveolar epithelia and pulmonary capillary basal lamina, fibrosis, centrilobular emphysema and pulmonary microangiopathy have been described in autopsy findings from diabetic individuals [19]. In addition, we have recently shown that type 2 diabetes is an independent risk factor for severe nocturnal hypoxaemia in obese patients [20]. However, there are no studies designed to investigate whether diabetes and the degree of glycaemic control are independent determinants of reduced pulmonary function in obese patients. For this purpose we designed a case-control study comparing respiratory function variables between diabetic and non-diabetic morbidly obese participants closely matched by the most important variables that could affect lung function. In addition, a multivariate regression analysis taking into account the potential confounders was also performed.

\section{Methods}

Design of the study and description of study population In this study we have investigated the effect of type 2 diabetes and the degree of glycaemic control on the lung function of morbidly obese participants following the Strengthening the
Reporting of Observational Studies in Epidemiology guidelines for reporting case-control studies [21].

We used the following formula for the sample size calculation:

$n=\frac{2(Z \alpha+Z \beta)^{2} \times s^{2}}{d^{2}}$

where the alpha level was set at $p<0.05(Z \alpha)$ and the minimum acceptable power level was considered to be 0.80 $(Z \beta)$, and where $s$ is the population standard deviation of $\mathrm{FEV}_{1}$ detected in a previous study [20], $d$ is the postulated effect size (we considered clinically significant a difference in $\mathrm{FEV}_{1}$ between the two groups of $15 \%$ ) and $n$ is the sample size.

$n=\frac{2(1.96+0.84)^{2} \times 16^{2}}{15^{2}}=18$.

On this basis, a total of 25 consecutive morbidly obese type 2 diabetic women without associated complications attending the outpatient obesity unit of a university hospital (Hospital Universitari Vall d'Hebrón, Barcelona, Spain) were recruited for the study over a 12-month period (cases). Women were selected for several reasons: (1) women represent $70-80 \%$ of patients attending our obesity unit; (2) men attending our obesity unit are generally older and have higher rates of co-morbidities (i.e. active smoking and coronary heart disease) that were exclusion criteria in the present study (see below); (3) hormonal status could affect susceptibility to lung dysfunction [22, 23].

We aimed to select two controls for every case and, consequently, 50 non-diabetic women attending the same obesity unit served as a control group. Controls were individually matched to cases by age, BMI and waist circumference. The main clinical features of the study population are displayed in Table 1. Data from forced spirometry and static volume measurements, as well as data from arterial blood gas sampling, were included in the analysis.

The exclusion criteria included history of smoking habit, chronic respiratory disease, asthma, cardiovascular disease, hearth failure, stroke and chest wall disease. A complete physical examination and chest radiography were performed on all patients included in the study.

Type 2 diabetes was defined according to the criteria recommended by the Expert Committee on the Diagnosis and Classification of Diabetes. On this basis, all type 2 diabetic cases were diagnosed by two fasting plasma glucose values equal or higher than $7.0 \mathrm{mmol} / 1$. Insulin resistance was determined by the HOMA (HOMA-IR) [24].

Informed written consent was obtained from all participants and the study was approved by the hospital's human ethics committee. 
Table 1 Main clinical characteristics of participants included in the study

\begin{tabular}{|c|c|c|c|c|}
\hline Variable & Type 2 diabetes & Non-type 2 diabetes & Mean difference $(95 \% \mathrm{CI})$ & $p$ value \\
\hline$n$ & 25 & 50 & - & - \\
\hline Age (years) & $44.0 \pm 8.7$ & $44.0 \pm 7.8$ & $0.0(-4.0$ to 3.9$)$ & 0.984 \\
\hline BMI $\left(\mathrm{kg} / \mathrm{m}^{2}\right)$ & $49.2 \pm 6.6$ & $49.0 \pm 5.1$ & $0.1(-2.8$ to 3.2$)$ & 0.912 \\
\hline Waist circumference $(\mathrm{cm})$ & $130.0 \pm 10.8$ & $129.6 \pm 9.6$ & $0.3(-4.5$ to 5.2$)$ & 0.883 \\
\hline Fasting glucose (mmol/l) & $8.6 \pm 2.7$ & $5.6 \pm 0.6$ & $2.9(1.8$ to 4.1$)$ & $<0.001$ \\
\hline $\mathrm{HbA}_{1 \mathrm{c}}(\%)$ & $7.5 \pm 1.4$ & $5.8 \pm 0.4$ & $1.7(1.1$ to 2.2$)$ & $<0.001$ \\
\hline HOMA-IR & $8.7 \pm 4.7$ & $5.3 \pm 3.6$ & $3.4(1.1$ to 5.6$)$ & 0.006 \\
\hline LDL-cholesterol (mmol/l) & $2.5 \pm 0.7$ & $2.6 \pm 0.6$ & $-0.1(-0.6$ to 0.3$)$ & 0.554 \\
\hline HDL-cholesterol (mmol/l) & $1.2 \pm 0.2$ & $1.3 \pm 0.5$ & $-0.1(-0.3$ to 0.1$)$ & 0.324 \\
\hline Triacylglycerol (mmol/l) & $2.0 \pm 0.9$ & $1.5 \pm 0.4$ & $0.5(0.1$ to 0.9$)$ & 0.006 \\
\hline Systolic blood pressure (mmHg) & $139.4 \pm 22.3$ & $135.8 \pm 18.8$ & $3.5(-6.5$ to 13.7$)$ & 0.506 \\
\hline Diastolic blood pressure (mmHg) & $87.5 \pm 15.2$ & $91.2 \pm 10.8$ & $-3.7(-10.1$ to 2.5$)$ & 0.241 \\
\hline Insulin treatment, $n(\%)$ & $5(20.0)$ & - & - & - \\
\hline Oral hypoglycaemic agents, $n(\%)$ & $14(56.0)$ & - & - & - \\
\hline Microangiopathy, $n(\%)^{\mathrm{a}}$ & $4(16.0)$ & - & - & - \\
\hline
\end{tabular}

Data are means $\pm \mathrm{SD}$

HOMA-IR, restricted to patients without current treatment with sulfonylureas or insulin $(n=63)$

${ }^{\text {a }}$ Non-proliferative retinopathy was present in three patients, whereas microalbuminuria was present in the last one

Measurement of respiratory function data Forced spirometry and static pulmonary volume measurements were performed using MasterLab apparatus (MasterLab; Jaeger; Würzburg, Germany). All tests were performed following guidelines proposed by the European Respiratory Society [25]. Static pulmonary volumes were measured using the plethysmography method. The theoretical values proposed by Roca et al. [26] were applied for spirometry, and values proposed by the European Respiratory Society for static volumes [25]. According to the Global Initiative for Chronic Obstructive Lung Disease (GOLD), an obstructive ventilatory pattern was established by the presence of an $\mathrm{FEV}_{1}$ $<80 \%$ of predicted, and $\mathrm{FEV}_{1}$ /forced vital capacity (FVC) ratio $<70 \%$ (GOLD guideline criteria for stage 2) [27]. The definition of a restrictive lung disease was an $\mathrm{FVC}<80 \%$ of predicted, with an $\mathrm{FEV}_{1} / \mathrm{FVC}$ ratio $>70 \%$ [28].

Room air arterial blood gas sampling was performed according to standard guidelines. Briefly, after patients had been sitting for at least $10 \mathrm{~min}$ samples were anaerobically drawn into preheparinised syringes following the administration of local anaesthesia in the area of the radial artery. Air bubbles were removed and each sample was taken immediately for analysis using an IL 682 Co-oximeter (Instrumentation Laboratories, Lexington, MA, USA).

Statistical analysis Normal distribution of the variables was evaluated using the Kolmogorov-Smirnov test. Data were expressed as the means $\pm \mathrm{SD}$. Comparisons between groups were made using the Student's $t$ test for continuous variables and the $\chi^{2}$ test for categorical variables. The relationship between the continuous variables was examined by the Pearson linear correlation test.

In addition, stepwise multiple linear regression analyses were performed. $\mathrm{FEV}_{1}$ and residual volume (RV) were considered as dependent variables, and the independent variables were: baseline clinical variables that could affect pulmonary function (BMI, waist circumference and age), along with variables associated with lung volumes in univariate analysis (fasting glucose and $\mathrm{HbA}_{1 \mathrm{c}}$ and HOMA-IR). Because a strong correlation between fasting blood glucose and $\mathrm{HbA}_{1 \mathrm{c}}$ was observed, two regression models taking separately into account each one of these variables were performed.

All $\mathrm{p}$ values were based on a two-sided test of statistical significance. Significance was accepted at the level of $p<$ 0.05. Statistical analyses were performed using the SSPS statistical package (SPSS, Chicago, IL, USA).

\section{Results}

The main pulmonary variables of the study population are presented in Table 2. Diabetic patients showed lower FEV 1 $(88.4 \pm 19.7 \%$ vs $100.0 \pm 12.4 \%$ of predicted; mean difference -11.6 [95\% CI -20.4 to -2.8$] ; p=0.011$ ), lower maximum mid-expiratory flow $\left(\mathrm{FEF}_{25-75}\right)(72.5 \pm 40.7 \%$ vs $97.8 \pm 24.4 \%$ of predicted; mean difference -25.3 [95\% CI -45.0 to -5.6$]$; $p=0.014)$ and lower $\mathrm{FEV}_{1} / \mathrm{FVC}$ ratio $(81.4 \pm 10.1 \%$ vs $85.8 \pm$ $5.02 \%$; mean difference $-4.4[95 \%$ CI -8.1 to -0.7$] ; p=$ 0.049 ) in comparison with non-diabetic patients. 
Table 2 Main pulmonary variables and arterial blood values of the participants included in the study

\begin{tabular}{|c|c|c|c|c|}
\hline Variable & Type 2 diabetes $(n=25)$ & Non-type 2 diabetes $(n=50)$ & Mean difference $(95 \% \mathrm{CI})$ & $p$ value \\
\hline \multicolumn{5}{|c|}{ Pulmonary function test } \\
\hline $\mathrm{FEV}_{1}(\%)^{\mathrm{a}}$ & $88.4 \pm 19.7$ & $100.1 \pm 12.4$ & $-11.6(-20.4$ to -2.8$)$ & 0.011 \\
\hline $\mathrm{FEF}_{25-75}(\%)^{\mathrm{a}}$ & $72.5 \pm 40.7$ & $97.8 \pm 24.4$ & $-25.3(-45.0$ to -5.6$)$ & 0.014 \\
\hline $\mathrm{FVC}(\%)^{\mathrm{a}}$ & $85.1 \pm 17.2$ & $93.3 \pm 20.1$ & $-8.2(-13.1$ to 0.5$)$ & 0.081 \\
\hline $\mathrm{FEV}_{1} / \mathrm{FVC}$ ratio $(\%)$ & $81.4 \pm 10.1$ & $85.8 \pm 5.2$ & $-4.4(-8.1$ to -0.7$)$ & 0.049 \\
\hline $\operatorname{TLC}(\%)^{\mathrm{a}}$ & $96.9 \pm 13.2$ & $94.4 \pm 9.4$ & $2.4(-2.8$ to 7.7$)$ & 0.354 \\
\hline $\operatorname{RV}(\%)^{\mathrm{a}}$ & $99.8 \pm 22.3$ & $80.3 \pm 15.2$ & $19.5(10.8$ to 28.3$)$ & $<0.001$ \\
\hline \multicolumn{5}{|l|}{ Arterial blood samples } \\
\hline $\mathrm{PaO}_{2}(\mathrm{mmHg})$ & $80.4 \pm 11.0$ & $82.1 \pm 8.7$ & $-1.6(-6.6$ to 3.3$)$ & 0.515 \\
\hline $\mathrm{PaCO}_{2}(\mathrm{mmHg})$ & $40.2 \pm 5.5$ & $38.3 \pm 4.0$ & $1.8(-0.5$ to 4.2$)$ & 0.126 \\
\hline
\end{tabular}

Data are means \pm SD

$\mathrm{PaCO}_{2}$, arterial carbon dioxide pressure; $\mathrm{PaO}_{2}$, arterial oxygen pressure; TLC, total lung capacity

${ }^{a}$ Value expressed as a percentage of the predicted value

In addition, clinically significant obstructive ventilatory pattern $\left(\mathrm{FEV}_{1}<80 \%\right.$ and $\mathrm{FEV}_{1} / \mathrm{FVC}$ ratio $\left.<70 \%\right)$ was more frequent in diabetic patients than in non-diabetic patients $(12.0 \%$ vs $0 \% ; p=0.012)$. In this regard a higher proportion of participants with $\mathrm{FEV}_{1}<80 \%(36.0 \%$ vs $10.0 \%$; $p=0.007), \mathrm{FEF}_{25-75}<65 \%$ (32.0\% vs $4.0 \%$; $p=$ $0.001)$ and $\mathrm{FEV}_{1} / \mathrm{FVC}$ ratio $<70 \%(16.0 \%$ vs $0 \%, p=$ $0.004)$ were identified among diabetic patients in comparison with non-diabetic patients. However, although the presence of a restrictive lung disease (FVC $<80 \%$ and $\mathrm{FEV}_{1} / \mathrm{FVC}$ ratio $>70 \%$ ) was higher than the obstructive pattern, no differences between groups were detected. In addition, in diabetic patients a greater RV $(99.8 \pm 22.4 \%$ vs $80.3 \pm 15.3 \%$ of predicted; mean difference 19.5 [95\% CI $10.8-28.3] ; p<0.001)$ was observed. No significant differences in arterial blood analyses $\left(\mathrm{PaO}_{2}\right.$ and $\left.\mathrm{PaCO}_{2}\right)$ were observed between groups.
Univariate analysis showed that in morbidly obese participants $\mathrm{FEV}_{1}$ negatively correlated with fasting glucose $(r=-0.283, p=0.014), \mathrm{HbA}_{1 \mathrm{c}}(r=-0.263, p=0.043)$ and HOMA-IR ( $r=-0.321, p=0.010$; Fig. 1$)$. In addition, $\mathrm{RV}$ was positively correlated with fasting glucose $(r=$ $0.454, p<0.001), \mathrm{HbA}_{1 \mathrm{c}}(r=0.346, p=0.006)$ and HOMAIR $(r=0.212, p=0.042$; Fig. 2$)$.

Multiple linear regression analyses showed that both fasting blood glucose and $\mathrm{HbA}_{1 \mathrm{c}}$ were independently related to $\mathrm{FEV}_{1}$ (see Electronic supplementary material [ESM] Table 1) and RV (ESM Table 2). In addition, HOMA-IR was also independently related to RV. Blood glucose levels and $\mathrm{HbA}_{1 \mathrm{c}}$ explained $7.6 \%$ and $8.5 \%$ of $\mathrm{FEV}_{1}$ variation, respectively. Regarding RV, fasting glucose and $\mathrm{HbA}_{1 \mathrm{c}}$ explained $17.6 \%$ and $6.2 \%$ of variation, respectively. Finally, HOMA-IR explained $12.0 \%$ of RV variation. a

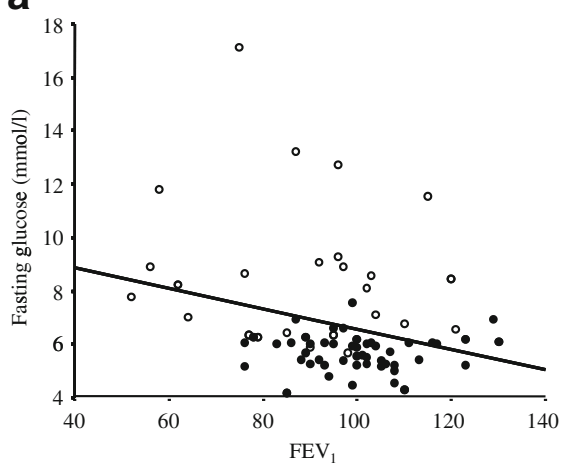

b

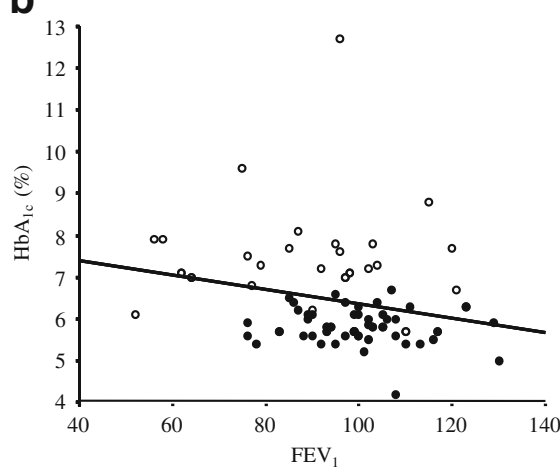

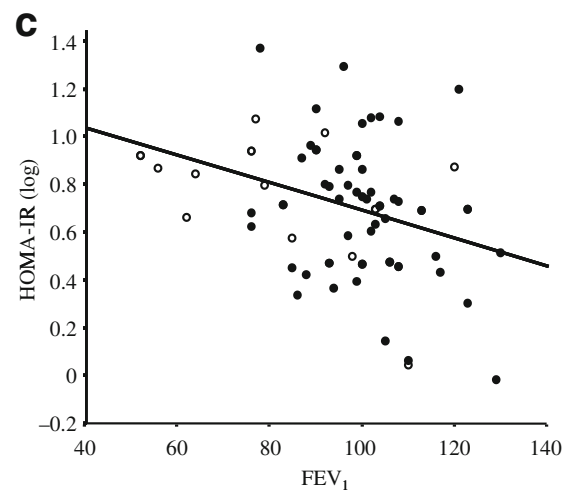

Fig. 1 Correlations of fasting glucose $(r=-0.283, p=0.014), \mathrm{HbA}_{1 \mathrm{c}}$ $(r=-0.236, p=0.043)$ and insulin resistance measured by the HOMAIR $(r=-0.321, p=0.010)$ with forced expiratory volume in $1 \mathrm{~s}$. White circles, type 2 diabetic patients; black circles, non-diabetic patients;
HOMA-IR, restricted to patients without current treatment with sulfonylureas or insulin $(n=63)$; $(\log )$, logarithmically transformed to base 10 
a

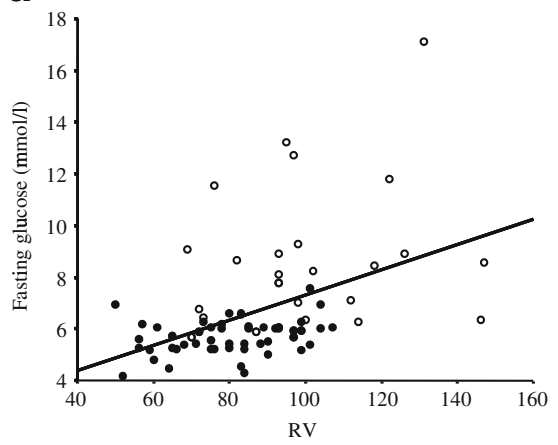

b

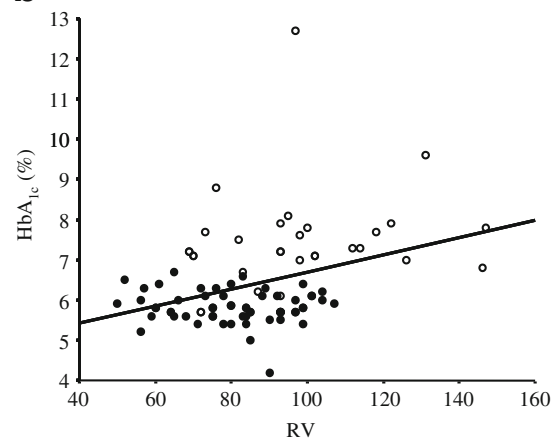

C

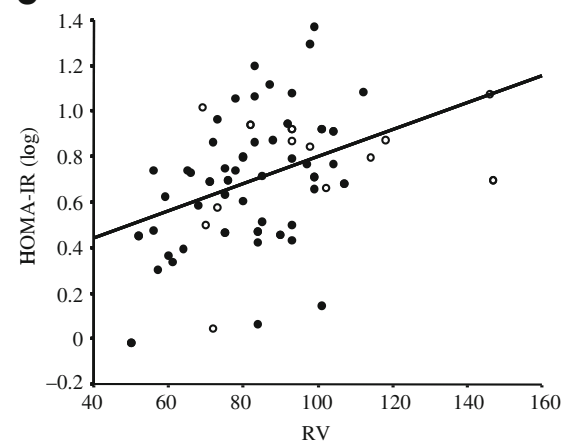

Fig. 2 Correlations of fasting glucose $(r=0.454, p<0.001), \mathrm{HbA}_{1 \mathrm{c}}$ $(r=0.364, p=0.001)$ and insulin resistance measured by the HOMAIR $(r=0.398, p=0.001)$ with RV. White circles, type 2 diabetic patients; black circles, non-diabetic patients; HOMA-IR, restricted to patients without current treatment with sulfonylureas or insulin $(n=63) ;(\log ), \operatorname{logarithmically~transformed~to~base~} 10$

\section{Discussion}

In the present study we provide, for the first time, evidence that diabetes is a risk factor for respiratory function impairment in morbidly obese women. The two main abnormalities detected were an obstructive ventilatory pattern and an increase in RV. As in diabetic patients a $10 \%$ decrease in $\mathrm{FEV}_{1}$ has been associated with a $12 \%$ increase in all-cause mortality [12], our results have serious implications for patients suffering from obesity and diabetes. Notably, we have found a relationship between the degree of blood glucose control (fasting glucose and $\mathrm{HbA}_{1 \mathrm{c}}$ ) and the impairment of pulmonary function tests. In addition, fasting glucose and $\mathrm{HbA}_{1 \mathrm{c}}$ contribute independently to lung volumes in multiple linear regression analysis. This finding strongly suggests that metabolic pathways related to hyperglycaemia are the main factor accounting for this impairment and points to the lung as a new target of long-term diabetic complications.

As expected, a restrictive rather than obstructive pattern was more frequent in obese patients, but no significant differences were observed between diabetic and non-diabetic participants. Autopsy findings and some cross-sectional studies have suggested an association between type 2 diabetes and lung damage $[8,9,12,19]$, but very little is known about the implications of diabetes for pulmonary function in obesity. Among the possible mechanisms involved in our results are: (1) the relation between type 2 diabetes and muscle strength; (2) the impairment in lung elastic properties; (3) defects in pulmonary surfactant; and (4) the presence of a low-grade chronic inflammation state.

Ventilatory function is partially determined by respiratory muscle strength. In this way, structural changes associated with muscle atrophy, augmented lipid deposition and decreased mitochondria as well as muscle fibre transformation have been described in type 2 diabetic patients [13]. In addition, in cross-sectional data collected from 655 men from the Normative Aging Study, skeletal muscle strength (as measured by handgrip dynamometry) was negatively associated with fasting insulin levels after adjustment for potential confounders [14], thus pointing to insulin resistance as a main factor involved in this impairment. Interestingly, we found a significant negative correlation between HOMA-IR and both $\mathrm{FEV}_{1}$ and RV. Furthermore, alterations in bronchial activity and respiratory muscle may be also related with autonomic and/or phrenic neuropathy [29].

Regarding the impairment of pulmonary elastic properties, there is little information, and what there is mostly refers to type 1 diabetic patients. Non-enzymatic glycosylation of collagen and elastin, which are essential components of the connective tissue, have been proposed as the main contributors to the impairment of pulmonary elastic properties that occurs in diabetes. In this regard, it has been reported that diabetic patients with severe limited joint mobility presented a significant decrease in $\mathrm{FVC}$ and $\mathrm{FEV}_{1}$, thus suggesting that altered respiratory mechanics could be a manifestation of a generalised disturbance in collagen metabolism [15]. In addition, it has been shown that type 1 diabetic patients treated with a standard twice-daily insulin injection regimen for 6 years presented a significant decrease in FVC in comparison with those who achieved near normoglycaemia treated with subcutaneous insulin infusion [16]. Consequently, diabetic microangiopathy has also been linked with altered lung volume, suggesting a relationship between alveolar and systemic microangiopathy [30]. Our findings reinforce the theory that poorly controlled diabetes is associated with an obstructive pattern of pulmonary abnormalities. Therefore, it is possible that type 2 diabetic patients exhale less air from the lungs at a slower rate than non-diabetic individuals and that this is associated with an increase in RV. In addition, these abnormalities could be involved in the propensity of diabetic patients to acquire lung infections. 
Defects in the bronchiolar surfactant layer, which is involved in maintaining airway stability and diameter, may be also considered a contributing factor to the impairment of calibre regulation in type 2 diabetes. When the alveolocapillary barrier is damaged, surfactant proteins leak into the bloodstream. A recent population-based random sample has described how increased circulating levels of surfactant protein A, the major surfactant-associated protein, were associated with altered glucose tolerance and insulin resistance [17]. Therefore, surfactant defects in diabetic individuals may also lead to an increase in airway resistance and to a reduction in $\mathrm{FEV}_{1}, \mathrm{FEF}_{25-75}$ and $\mathrm{FEV}_{1}$ / FVC ratio, as observed in our patients. In addition, as glucagon-like peptide 1 has been shown to play a role in the stimulation of surfactant production [31], its underlying deficit in type 2 diabetes could also enhance the airway resistance observed in these patients. However, the beneficial effects on pulmonary function using incretin-based therapies remain to be elucidated.

Finally, the presence of low-grade chronic inflammation could also be considered as a contributing factor to pulmonary abnormalities detected in morbidly obese diabetic patients. Similarly to the active implication of proinflammatory adipokines in the development of insulin resistance associated with obesity, a potential interaction between abnormal adipose tissue activity, systemic inflammation and pulmonary function has been suggested [3]. In this regard, data from the Third National Health and Nutrition Examination Survey showed how participants with chronic airflow obstruction had higher circulating levels of leucocytes, C-reactive protein and fibrinogen than those without airflow obstruction [18]. Given that proinflammatory cytokine levels have been reported to be higher in morbidly obese type 2 diabetic individuals compared with those without diabetes [32], it is possible that this could be a contributing factor to the impairment of respiratory function detected in type 2 diabetes.

There are some potential limitations that should be taken into account in evaluating the results of our study. First, this was a cross-sectional study and, therefore, a causal link between type 2 diabetes and impaired pulmonary function cannot be drawn. However, the lack of differences in arterial blood gas sampling between groups and the significant correlation between lung volume and metabolic variables point to diabetes as the primary event. In this regard, studies aimed at determining whether the normalisation of blood glucose levels could improve functional lung variables are warranted. Second, we have not excluded autonomic neuropathy in diabetic patients, and therefore alterations in bronchial activity and respiratory muscle attributable to its presence cannot be ruled out. Third, recent data suggest that obesity is often associated with asthma [33]. However, although we have not specifically evaluated the presence of bronchial hyperreactivity in our patients, the exclusion of participants with self-reported asthma makes this potential bias very unlikely. Finally, in the present study only a selected population of morbidly obese women was included. Although our results and the possible mechanisms involved in the negative effect of type 2 diabetes on pulmonary function might also be transferable to men and less obese individuals, further studies in these populations are required.

In conclusion, the presence of type 2 diabetes and the degree of glycaemic control are related to respiratory function impairment, at least in morbidly obese women. Therefore, the impact of type 2 diabetes on pulmonary function should be considered by those providing care for obese people. Future studies to define not only the mechanisms involved in the pulmonary dysfunction associated with type 2 diabetes, but also to determine whether blood glucose control could prevent lung injury, are needed.

Acknowledgements This study was supported by a grant from the Instituto de Salud Carlos III (Fondo de Investigación Sanitaria, PI060476). CIBER de Diabetes y Enfermedades Metabólicas Asociadas (CIBERDEM) and CIBER de Enfermedades Respiratorias (CIBERES) are an initiative of the Instituto Carlos III.

Duality of interest The authors declare that there is no duality of interest associated with this manuscript.

\section{References}

1. World Health Organization (2006) Obesity and overweight. Fact Sheet No. 311. Available from www.who.int/mediacentre/fact sheets/fs311/en/index.html, accessed 1 February 2009

2. Formiguera X, Canton A (2004) Obesity: epidemiology and clinical aspects. Best Pract Res Clin Gastroenterol 18:1125-1146

3. McClean KM, Kee F, Young IS, Elborn JS (2008) Obesity and the lung: epidemiology. Thorax 63:649-654

4. Steele RM, Finucane FM, Griffin SJ, Wareham NJ, Ekelund U (2009) Obesity is associated with altered lung function independently of physical activity and fitness. Obesity (Silver Spring) 17:578-584

5. Biring MS, Lewis MI, Liu JT et al (1999) Pulmonary physiologic changes of morbid obesity. Am J Med Sci 318:293-297

6. Chen Y, Rennie D, Cormier YF, Dosman J (2007) Waist circumference is associated with pulmonary function in normalweight, overweight, and obese subjects. Am J Clin Nutr 85:35-39

7. Schünemann HJ, Dorn J, Grant BJ, Winkelstein W Jr, Trevisan M (2000) Pulmonary function is a long-term predictor of mortality in the general population: 29-year follow-up of the Buffalo Health Study. Chest 118:656-664

8. Barrett-Connor E, Frette C (1996) NIDDM, impaired glucose tolerance, and pulmonary function in older adults. The Rancho Bernardo Study. Diabetes Care 19:1441-1444

9. Davis TME, Knuiman M, Kendall P, Vu H, Davis WA (2000) Reduced pulmonary function and its associations in type 2 diabetes: the Fremantle Diabetes Study. Diabetes Res Clin Pract 50:153-159 
10. Mannino DM, Thorn D, Swensen A, Holguin F (2008) Prevalence and outcomes of diabetes, hypertension and cardiovascular disease in COPD. Eur Respir J 32:962-969

11. Yeh HC, Punjabi NM, Wang NY et al (2008) Cross-sectional and prospective study of lung function in adults with type 2 diabetes: the Atherosclerosis Risk in Communities (ARIC) Study. Diabetes Care 31:741-746

12. Davis WA, Knuiman M, Kendall P, Grange V, Davis TME (2004) Glycemic exposure is associated with reduced pulmonary function in type 2 diabetes. The Fremantle Diabetes Study. Diabetes Care 27:752-757

13. Sun Z, Liu L, Liu N, Liu Y (2008) Muscular response and adaptation to diabetes mellitus. Front Biosci 13:4765-4794

14. Lazarus R, Sparrow D, Weiss ST (1997) Handgrip strength and insulin levels: cross-sectional and prospective associations in the Normative Aging Study. Metabolism 46:1266-1269

15. Schnapf BM, Banks RA, Silverstein JH, Rosenbloom AL, Chesrown SE, Loughlin GM (1984) Pulmonary function in insulin-dependent diabetes mellitus with limited joint mobility. Am Rev Respir Dis 130:930-932

16. Ramirez LC, Dal Nogare A, Hsia C et al (1991) Relationship between diabetes control and pulmonary function in insulin dependent diabetes mellitus. Am J Med 91:371-376

17. Fernández-Real JM, Chico B, Shiratori M, Nara Y, Takahashi H, Ricart W (2008) Circulating surfactant protein A (SP-A), a marker of lung injury, is associated with insulin resistance. Diabetes Care 31:958-963

18. Sin DD, Man SF (2003) Why are patients with chronic obstructive pulmonary disease at increased risk of cardiovascular diseases? The potential role of systemic inflammation in chronic obstructive pulmonary disease. Circulation 107:1514-1519

19. Nicolaie T, Zavoianu C, Nuta P (2003) Pulmonary involvement in diabetes mellitus. Rom J Intern Med 41:365-374

20. Lecube A, Sampol G, Lloberes P et al (2009) Diabetes is an independent risk factor for severe nocturnal hypoxemia in obese patients. A case-control study. PloS ONE 4:e4692

21. von Elm E, Altman DG, Egger M, Pocock SJ, Gøtzsche PC, Vandenbroucke JP, STROBE Initiative (2007) The Strengthening the Reporting of Observational Studies in Epidemiology (STROBE) statement: guidelines for reporting observational studies. Lancet 370:1453-1457

22. Carey MA, Card JW, Voltz JW, Germolec DR, Korach KS, Zeldin DC (2007) The impact of sex and sex hormones on lung physiology and disease: lessons from animal studies. Am J Physiol Lung Cell Mol Physiol 293:272-278

23. Card JW, Zeldin DC (2009) Hormonal influences on lung function and response to environmental agents: lessons from animal models of respiratory disease. Proc Am Thorac Soc 6:588-595

24. McLaughlin T, Abbasi F, Cheal K, Chu J, Lamendola C, Reaven $\mathrm{G}$ (2003) Use of metabolic markers to identify overweight individuals who are insulin resistant. Ann Intern Med 139:802809

25. Quanjer PH, Tammeling GJ, Cotes LE, Pedersen OF, Peslin R, Yernault JC (1993) Lung volumes and forced ventilatory flows. Report working party standardization of lung function tests, European Community for Steel and Coal. Official Statement of the European Respiratory Society. Eur Respir J 16(suppl):5-40

26. Roca J, Sanchis J, Agusti-Vidal A et al (1986) Spirometric reference values from a Mediterranean population. Bull Eur Physiopathol Respir 22:217-224

27. Pauwels RA, Buist AS, Calverley PM, Jenkins CR, Hurd SS, GOLD Scientific Committee (2001) Global strategy for the diagnosis, management, and prevention of chronic obstructive pulmonary disease. NHLBI/WHO Global Initiative for Chronic Obstructive Lung Disease (GOLD) Workshop summary. Am J Respir Crit Care Med 163:1256-1276

28. Gold WM (2000) Pulmonary function testing. In: Murray JF, Nadel JA, Mason RJ, Boushey HA (eds) Textbook of respiratory medicine, 3rd edn. Elsevier Saunders, Philadelphia, pp 781-881

29. Fleming DM, Crombie DL, Cross KW (1991) Disease concurrence in diabetes mellitus: a study of concurrent morbidity over 12 months using diabetes mellitus as an example. J Epidemiol Community Health 45:73-77

30. Chance WW, Rhee C, Yilmaz C et al (2008) Diminished alveolar microvascular reserves in type 2 diabetes reflect systemic microangiopathy. Diabetes Care 31:1596-1601

31. Ahrén B (2004) GLP-1 and extra-islet effects. Horm Metab Res 36:842-845

32. Bullo M, García-Lorda P, Salas-Salvadó J (2002) Plasma soluble tumor necrosis factor alpha receptors and leptin levels in normalweight and obese women: effect of adiposity and diabetes. Eur J Endocrinol 146:325-331

33. Murugan AT, Sharma G (2008) Obesity and respiratory diseases. Chron Respir Dis 5:233-242 